\title{
Mapping of Australian Fire Weather Potential: Observational and modelling studies
}

\author{
$\underline{\text { Sanabria L.A. }}{ }^{\mathrm{a}, \mathrm{b}}$, Cechet R.P. ${ }^{\mathrm{a}, \mathrm{b}}$ and Li J. ${ }^{\mathrm{a}}$ \\ ${ }^{a}$ Geoscience Australia, Canberra. \\ ${ }^{b}$ Bushfire Cooperative Research Centre, Melbourne. \\ Email: augusto.sanabria@ga.gov.au
}

\begin{abstract}
Indicators of fire weather potential are used by fire management agencies to assess fire weather danger in order to issue public warnings, ban the lighting of open fires, and also boost procedures to mitigate the consequences of a bushfire if such an event occurs.

The most widely used fire weather danger indices in Australia are the McArthur Forest Fire Danger Index (FFDI) and the Grass Fire Danger Index (GFDI). These indices can be calculated at weather stations using measurements of weather variables and fuel information. The planning and emergency authorities, however, require the spatial distribution of these indices over the whole country. In this paper we present a methodology to calculate the spatial distribution of the most widely used fire weather danger index in Australia: the FFDI. In particular we are interested in the long-term trend of extreme values of the FFDI. This indicator of fire weather conditions is assessed by calculating the return period (RP) of its extreme values by fitting extreme value distributions to records of FFDI at a subset of 38 Bureau of Meteorology (BoM) automatic weather stations around Australia. The spatial distribution of the return period was obtained by applying an advanced spatial interpolation algorithm to the recording stations measurements. One of the limitations of this approach is that is does not take into account the impact of climate change on the longterm fire weather potential. To overcome this issue, we present a methodology to calculate RP of FFDI using climate simulated (modelled) data.
\end{abstract}

Comparison of FFDI based on interpolated data from observational studies with FFDI calculated from climate model simulations for the same period (current climate), shows that both models produce similar patterns of FFDI distribution. Both models show that the highest FFDI over large parts of southern Australia occurs during the summer months whilst in northern Australia the highest values occur in spring. The results also show that the FFDI in eastern Australia, the most populated region of the country, is higher inland than in the coastal areas particularly during spring and summer.

These results give us confidence that we can use climate model simulations to study the trend of FFDI extremes in the final part of the $21^{\text {st }}$ century.

Keywords: $\quad$ Bushfire risk, fire weather, climate model simulations, fire forest danger index. 


\section{INTRODUCTION}

This paper discusses models to assess Australia's fire weather potential (FWP). FWP refers to the set of climatic conditions which can lead to bushfires when the other two elements of the bushfire development process are present: fuel load and ignition. Determining high fire weather potential for a region allows planners to consider whether the proposed use for a land parcel is appropriate, and also allows the emergency authorities to consider how they can be better prepared to mitigate the consequences of a bushfire if such an event occurs.

FWP is assessed by calculating return periods of the McArthur Forest Fire Danger Index (FFDI), the most widely used indicator of fire weather danger in the Eastern states of Australia (Matthews, 2009). Lucas (2010) developed a historical fire weather data set for Australia based on records from a subset of 78 Bureau of Meteorology (BoM) automatic weather stations located around Australia. These data contain records of daily weather variables which influence fire weather conditions such as temperature, relative humidity, drought factor, daily rainfall and wind speed and direction. Based on these records, Lucas (2010) calculated daily maximum FFDI and Grassland Fire Danger Index (GFDI), and developed a data set which advanced the understanding of conditions prone to producing extreme fire weather danger. Planning and emergency authorities, however, require the spatial distribution of these indices and their long-term trend over the whole country. In this paper we attempt to close the gap between point and region-based FFDI by calculating observational-based return periods of extreme FFDI and presenting the spatial distribution of these return periods over the Australian continent.

An assessment of quality of the data sets compiled by Lucas was undertaken by Clarke et al. (2012). They found that only 38 of the 78 stations can be considered of good quality. For this reason in this study we utilise only the 38 quality stations for the spatial analysis as discussed in section 3 . To move from a stationbased RP to a spatially distributed RP we used an advanced spatial interpolation algorithm (Li et al., 2011a). This algorithm however, does not allow us to study the impact of climate change on FWP. For this type of study we have developed an alternative approach which calculates FWP using climate simulated (modelled) data of current climate conditions (later part of the $20^{\text {th }}$ century).

This study is important in the process of assessing the fire weather danger faced by communities that are located some distance from the nearest meteorological observing stations. It is also possible to obtain a preliminary and empirical calculation of the risk to these communities posed by high FFDI by employing the link between high FFDI with house loss for the Australian region as detailed in Blanchi et al. (2010).

In practical applications the actual fire weather potential for a region depends on the type of vegetation in the region. In some regions an FFDI would not be the most appropriate index, for instance in the savannas of northern Australia which are dominated by grassland. In these cases the GFDI would be a more appropriate index to use (Cheney and Sullivan, 1997). In more complex vegetations a combination of both forest and grassland indexes weighted by a factor, could be a better indicator of fire danger (Cechet et al., 2013).

\section{RETURN PERIOD OF FFDI}

Natural hazards can be quantified by using the Average Recurrence Interval (ARI) more commonly known as the return period (RP) of the natural phenomenon. If a given value of the phenomenon, termed 'return level', is exceeded with probability ' $p$ ' on average once a year, the RP corresponding to this return level is $1 / p$ years (Coles, 2001). For instance, if the average annual probability of exceeding a gust wind speed of $45 \mathrm{~m} / \mathrm{s}$ at some location is 0.002 , the 500 -year RP $(1 / 0.002)$ of gust wind speed at the location is $45 \mathrm{~m} / \mathrm{s}$, i.e. it is expected that the value $45 \mathrm{~m} / \mathrm{s}$ is exceeded, on average, once every 500 years.

The concept of RP is particularly useful to assess the long-term tendency of extreme values, the values of interest in hazard studies. In this case, we can fit an extreme value distribution to the tail of the data and extrapolate to a range of years well beyond the number of years available in the dataset (Coles, 2001).

Based on McArthur's work, Noble et al. (1980) developed an expression that relates the climatology with the forest dryness conditions at a given region,

$$
F F D I=2 * \exp (0.987 * \ln (D F)-0.0345 * R H+0.0338 * T+0.0234 * W S-0.45
$$

where $\mathrm{DF}=$ Drought factor (a measure of forest dryness conditions), $\mathrm{RH}=$ Relative humidity (\%),

$\mathrm{T}=$ temperature $\left({ }^{\circ} \mathrm{C}\right)$ and $\mathrm{WS}=$ wind speed $(\mathrm{km} / \mathrm{h})$. 
Figure 1 shows the RP of FFDI at the Sydney airport station. The circles are RP calculated from the observations and the solid line is the RP calculated using the Generalised Pareto Distribution (GPD). The dashed lines indicate the $95 \%$ confidence interval (CI) for the GPD fit. Note that the accuracy of the results decrease for higher RP, indicating a higher degree of uncertainty when making inferences beyond the range of the data (40 years). To illustrate the methodology for spatial interpolation, the 50 -yr RP of FFDI will be discussed in this paper as it represents the key RP for planners and emergency managers. The methodology could be extended to 100-yr or 500-yr RP if applications for these RPs are determined.

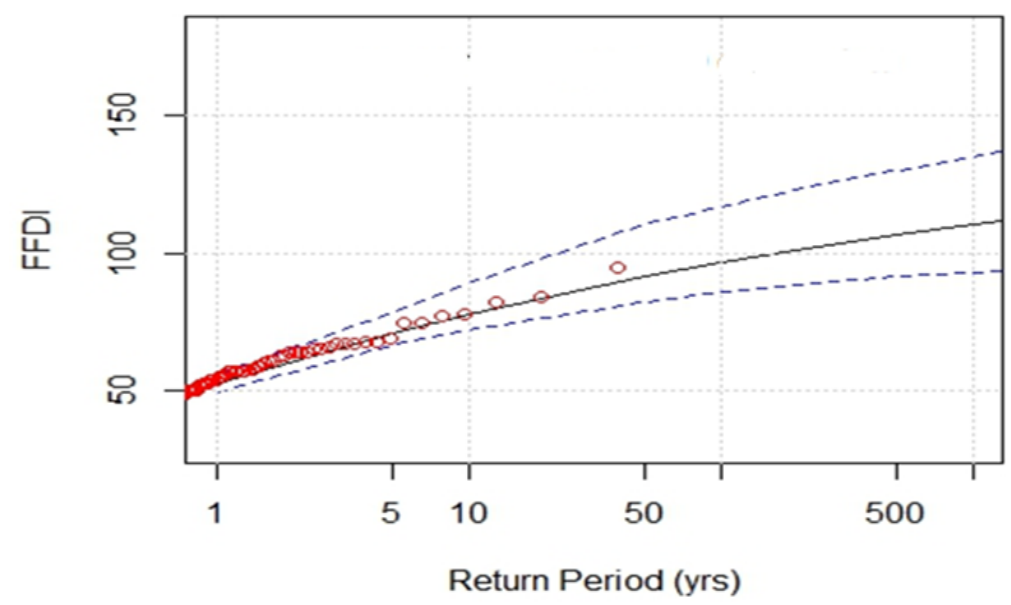

Figure 1. RP of FFDI at Sydney airport (solid line) with the 95\% CI (shown as the dashed lines).

In this study we assume that the time series of FFDI, calculated from 40 years of observations, is stationary, i.e. the parameters of the distribution do not change over this period. Possible change of these parameters due to seasonal characteristics is studied by calculating seasonal RP of FFDI (Section 4). Changes due to climate change are studied by using climate model simulations (Section 5).

\section{ADVANCED INTERPOLATION ALGORITHMS}

A new generation of algorithms to calculate the spatial distribution of point-based values has been developed by Li et al (2011a) based on a combination of conventional algorithms, such as Inverse Distance Weighting (IDW) and Ordinary Kriging (OK), with machine learning algorithms, such as random forest (RF). Li et al., (2011a) have shown that these hybrid algorithms give more accurate results than the conventional algorithms over a wide range of conditions. Two hybrid algorithms were tested in this project: RF with IWD and RF with $\mathrm{OK}$.

The spatial interpolation algorithm requires a number of gridded auxiliary variables which are considered to influence FFDI. The introduction of secondary variables in spatial prediction may be important if correlation is high ( $\mathrm{Li}$ et al., 2011a). Climate variables, in particular, show a strong dependency on topography and hence it is important to incorporate topographical information in the interpolation of these types of variables (Hong et al., 2005). The technique discussed in this paper allows the incorporation of a large number of auxiliary variables and therefore it is especially suited for the interpolation of climatic variables. Publicly available data sets were used in this study; most of them were recorded by BoM.

The auxiliary variables from BoM (2012) utilised in this study are: annual and seasonal rainfall, temperature, relative humidity, evaporation, station location (latitude and longitude), and maximum and minimum temperature. Other auxiliary variables utilised in this study are: mean wind speed obtained from McVicar et al. (2008), enhanced vegetation index (EVI) obtained from Lymburner et al. (2010), and elevation obtained from Gallant et al. (2011). Together 35 secondary variables were used for the interpolation using the hybrid algorithms (Sanabria et al., 2013).

The quality of the spatial distribution can be assessed by calculating the cumulative sum of the difference between observed and predicted values in all stations. Table 1 shows the Relative Root Mean Squared Error (RRMSE) and the Relative Mean Absolute Error (RMAE), two widely used indicators of the prediction 
accuracy. Errors around 25\% are considered normal for this type of application (Li et al., 2011). Table 1 indicates that the hybrid RF-IDW algorithm produces the best results.

Figure 2 shows the spatial distribution of the 50-yr RP of FFDI using the RF-IDW algorithm. The black circles indicate the location of the 38 recording stations.

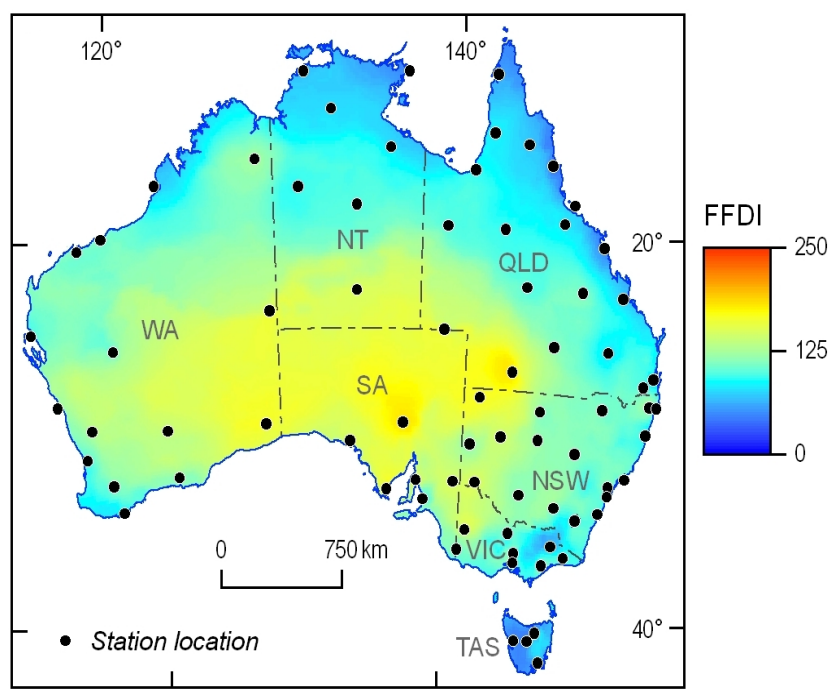

Table 1. Assessing the quality of the spatial prediction of FFDI

\begin{tabular}{|l|l|l|}
\hline Error & RF-IDW & RF-OK \\
\hline $\begin{array}{l}\text { RMAE } \\
(\%)\end{array}$ & 16.6 & 17.3 \\
\hline $\begin{array}{l}\text { RRMSE } \\
(\%)\end{array}$ & 21.5 & 22.0 \\
\hline
\end{tabular}

Figure 2. Spatial distribution of the 50-yr RP of FFDI using the RF-IDW algorithm.

\section{SEASONAL CHARACTERISTICS OF FFDI}

Given the large range of climates with varying seasonal patterns and vegetation types characterising Australia, it is important to show the variation of fire weather extremes in each season. Extreme fire weather conditions in Australia are highly dependent on the season; comparison of regional extreme fire weather in each season could provide additional information for emergency managers to plan bushfire mitigation measures. In data was split in to the four seasons and the procedure discussed above was repeated. Figure 4 shows the seasonal 50-yr RP of FFDI. For a more detailed assessment of fire weather danger we present the 50-yr RP map using a discrete scale similar to the scale used by emergency authorities (BoM, 2013). In the original calculation of FFDI by McArthur, the FFDI value was calibrated to have a maximum of 100 for what was considered at the time the worst possible fire weather conditions in Australia. In reality, however, Lucas (2010) has shown that this value has been exceeded in severe to extreme fire weather situations. In this work therefore we use an extended scale with the highest value indicating FFDI greater than 150 .

The highest value for the 50-yr RP of FFDI over large parts of Australia is observed in summer and spring (for the northern part of the continent), whilst the lowest value of the 50-yr RP is observed in winter (as expected). Different regional weather patterns reflect the varied fire seasons. The northern part of the Australian continent typically experiences most of its fires in winter and spring. For most of southern Australia, the danger period is summer and autumn. For Tasmania and the southern-most coastal part of the continent, the summer season dominates the period of concern regarding bushfires. New South Wales and southern Queensland usually experience the peak hazard of extreme fire weather in spring and early summer. It should be noted that the hazard of extreme fire weather along the southeastern coast of Australia (including all of New South Wales) is higher inland than in the coastal areas particularly in summer and spring.

\section{RP OF FFDI USING “CURRENT CLIMATE” SIMULATED DATA}

To develop a model to calculate FFDI based on climate model simulations we use the high resolution climate simulations generated by the 'Climate Futures for Tasmania' (CFT) project (Corney et al., 2010). The CFT team generated the simulations using dynamical downscaling of six general circulation models (GCM) and the NCEP/NCAR reanalysis data (2013), using CSIRO's Conformal Cubic Atmospheric Model (McGregor et al., 2001). 

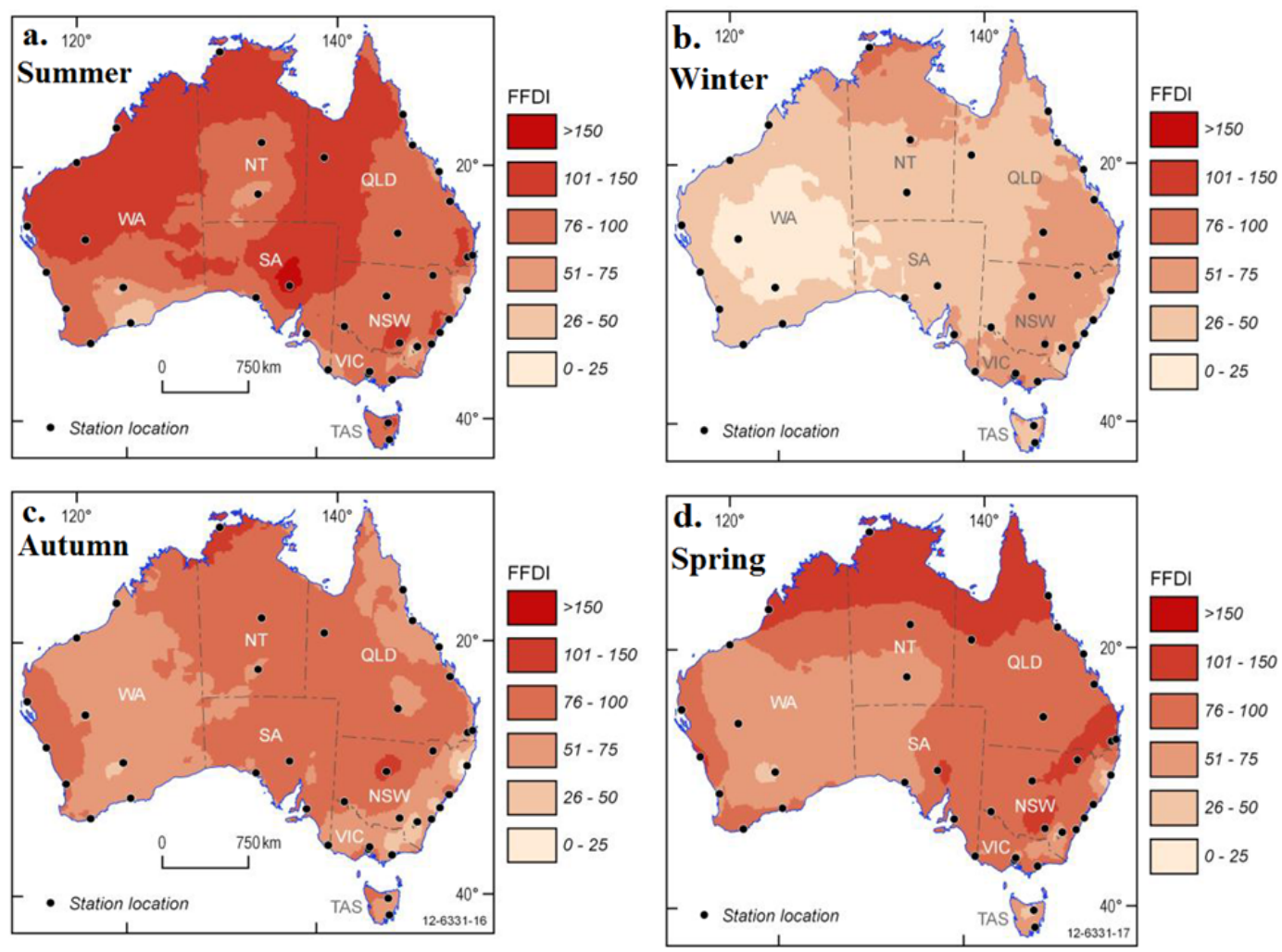

Figure 4. The predicted spatial pattern of 50-year RP of FFDI in a) Summer (December, January and February), b) Winter (June, July and August), c) Autumn (March, April and May), and d) Spring (September, October and November) using RF-IDW.

The simulated climate-model data include relative humidity at different pressure levels at 3-hour intervals. To calculate maximum FFDI using (1), we extracted the level 1 relative humidity calculated at 06 hours UTC time, corresponding to $4 \mathrm{PM}$ in Australian south eastern states. At this time of the day RH tends to be lowest and hence the FFDI tends to peak (Lucas et al., 2007). For temperature, the maximum daily screen temperature was used. For wind speed we used the maximum daily $10 \mathrm{~m}$ height (open terrain) extracted from the simulations. Both the climate simulations and the BoM-provided DF dataset had to be re-gridded to a common grid of $0.5 \times 0.5$ degrees. The drought factor is a dimensionless variable ranging between 0 and 10 representing the amount of fine fuel that would be available to be consumed in the flaming front of a bushfire (McCarthy 2003). The BoM has calculated gridded daily drought factors over Australia since 1964 at a resolution of $0.25^{\circ}$ (Finkele at al. 2006), and these data were employed when calculating FFDI.

The CFT simulations relevant for this project cover only the south-eastern part of Australia. Figure 5a shows the 50-yr RP of FFDI calculated from the CFT simulation driven by the NCEP/NCAR reanalysis data. Thirty years of climate-model simulated data from 1965 were used in order to study the behaviour of FFDI under current climate conditions. Note the empty polygons in the central and western parts of Australia as the drought factor data provided by BoM does not include values in these regions. Figure $5 \mathrm{~b}$ shows the difference in percentage between observed and climate simulated RP of FFDI (difference between Figure 2 and Figure 5a).

The pattern of fire weather potential from observed and simulated data was consistent with very high values in the central part of southern Australia and medium values in the south-eastern corridor. Figure 5b shows the bias (\%) of simulated FFDI when compared against observations. High positive bias occurs in the regions of high FFDI indicating a tendency of the simulations to underestimate the FFDI. In the regions of medium FFDI the reverse can be observed; the simulations overestimate the FFDI. Figure 5b shows that it is necessary to develop a bias correction procedure in order to have confidence in the climate simulation based model to study fire weather potential in Australia 


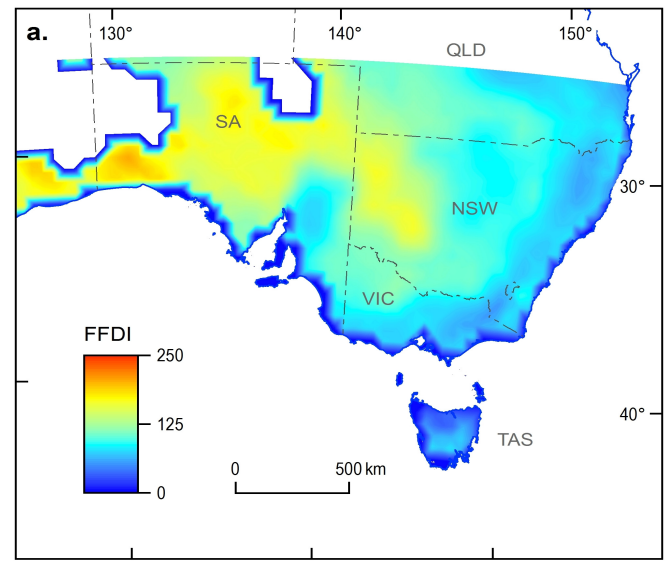

Figure 5a. 50-yr RP of FFDI using climate simulations.

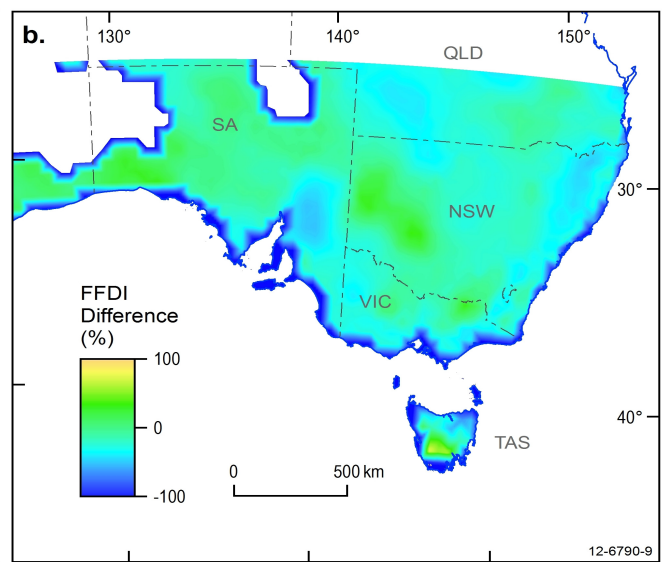

Figure $5 \mathrm{~b}$. Difference $(\%)$ between observed and simulated 50-yr RP of FFDI.

\section{CONCLUSIONS}

A methodology to study the long-term tendency of extremes of fire weather potential has been presented. Implementation of this methodology in Australia shows that fire weather is highly dependent on the season and the region of the country: in the northern states of Australia the bushfire season extends from spring to summer; for most of southern Australia the danger period is summer and autumn; in Tasmania the bushfire season occurs in summer.

Mapping of extreme fire weather potential can be an important tool for bushfire risk management. It will assist emergency managers to prepare mitigation procedures for each region of Australia in the season of high FFDI.

The impact of climate change on the long-term tendency of FWP can be studied using climate model simulations. Comparison of FWP using observations and climate model simulations show that both models produce similar patterns of Fire Weather danger but climate simulation results show a bias which needs to be corrected. We are developing an algorithm for bias correction of climate simulation based RP calculation in order to produce a more robust model for FWP. Once the model has been calibrated we can study the impact of climate change on FFDI using simulations of a range of $21^{\text {st }}$ century climate projections.

\section{REFERENCES}

Blanchi, R., Lucas, C., Leonard, J., Finkele, K. (2010). Meteorological conditions and wildfire-related house loss in Australia. Int. J. of Wildland Fire 2010, 19, 914-926.

BoM (Australian Bureau of Meteorology). (2012). Climate and Past Weather. http://wwwcluster.bom.gov.au/climate/ Accessed May 2013.

BoM. (2013). Fire weather warnings. http://www.bom.gov.au/weather-services/bushfire. Accessed Sept. 2013.

Cechet R.P., L.A. Sanabria and I. French (2013) High-resolution bushfire hazard mapping of the current and future climate to inform planning for the Rockhampton region. Submitted for presentation to MODSIM2013, Modelling and Simulation Society of Australia and New Zealand (MSSANZ) Conference, Adelaide

Cheney P., Sullivan A. (1997). Grassfires: Fuel, Weather and Fire Behaviour. CSIRO Publishing, Melbourne. $110 \mathrm{pp}$.

Clarke, H.G., Lucas, C., Smith, P.L. (2012). Changes in Australian fire weather between 1973 and 2010, International Journal of Climatology, DOI: 10.1002/joc.3480

Coles, S., (2001). An Introduction to Statistical Modeling of Extreme Values. London: Springer.

Corney, S.P., Katzfey, J., McGregor, J., Grose, M.R., Bennett, J., White, C.J., Holz, G., Gaynor, S.M., Bindoff, N.L. 2010. "Climate Futures for Tasmania technical report: climate modelling”. Antarctic Climate and Ecosystems Cooperative Research Centre, Hobart, Tasmania.

Finkele, K., Mills, G.A., Beard, G. and Jones, D.A. (2006). National Daily Gridded Soil Moisture Deficit and 
Drought Factors for Use in Prediction of Forest Fire Danger Index in Australia. Bureau of Meteorology Research Centre, Research Report No 119.

Gallant, J.C., Dowling, T.I., Read, A.M., Wilson, N., Tickle, P., Inskeep, C. (2011). 1-second SRTM Derived Digital Elevation Models User Guide. Geoscience Australia

Hong Y., Nix H.A. Hutchinson M.F. Booth T.H. (2005). Spatial Interpolation of Monthly Mean Climate Data for China. Int. J. Climatol 25:1369-1379.

Li, J., Heap A.D. (2011). A review of comparative studies of spatial interpolation methods in environmental sciences: Performance and impact factors. Ecological Informatics 6: 228 - 241.

Li, J., Heap A.D., Potter A., Daniell J. (2011a). Application of machine learning methods to spatial interpolation of environmental variables. Environmental Modelling and Software 26: 1647-1659.

Lucas, C., Hennessy, K., Mills, G., Bathols, J., 2007. Bushfire weather in southeast Australia: Recent trends and projected climate change impacts. Bushfire CRC and Australian Bureau of Meteorology. Consultancy report prepared for the Climate Institute of Australia.

Lucas, C. (2010). On developing a historical fire weather data-set for Australia. Australian Meteorological and Oceanographic Journal, 60: 1-14.

Matthews, S., 2009. A Comparison of Fire Danger Rating Systems for Use in Forests. Australian. Meteorological and Oceanographic Journal 58, 41-48.

McCarthy G (2003). Drought Factor (fine fuel consumption) prediction from field measurement of Fine Fuel Moisture Content. Forest Science Centre. Dep. of Sustainability and Environment.

McGregor J.L. and Dix M.R. (2001). The CSIRO Conformal-Cubic Atmospheric GCM. Proc. IUTAM Symposium on Advances in Mathematical Modelling of Atmosphere and Ocean Dynamics.

McVicar, T.R., Van Niel, T.G., Li, L.T., Roderick, M.L., Rayner, D.P., Ricciardulli, L.,Donohue, R.J. (2008). Wind speed climatology and trends for Australia, 1975-2006: Capturing the stilling phenomenon and comparison with near-surface reanalysis output. Geophysical Research Letters, 35, no. L20403, pp. $1-6$.

Lymburner, L., Tan, P., Mueller, N., Thackway, R., Lewis, A., Thankappan, M., Randall, L., Islam, A., Senarath, U., (2010). 250 metre Dynamic Land Cover Dataset (1st Edition), Geoscience Australia, Canberra.

NCEP/NCAR Reanalysis Project (2013). http://www.esrl.noaa.gov/psd/data/reanalysis/reanalysis.shtml. Accessed July 2013.

Noble, I.R., Bary, G.A.A., Gill, A.M. (1980). McArthur's fire danger meters expressed as equations. Australian Journal of Ecology, 5, pp. 201 - 203.

Sanabria L.A., Qin, X., Li, J., Cechet R.P., Lucas, C. (2013). Spatial interpolation of McArthur's forest fire danger index across Australia: Observational study. I. J. of Environmental Modelling and Software. Vol. 50, 37-50. http://authors.elsevier.com/sd/article/S1364815213001916

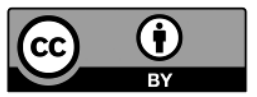

(C) Commonwealth of Australia (Geoscience Australia) 2013.

This publication is provided under a Creative Commons Attribution 3.0 Australia Licence with the permission of the CEO of Geoscience Australia. 